\title{
Cryptotanshinone targets tumor-initiating cells through down-regulation of stemness genes expression
}

\author{
YING ZHANG $^{1,2}$, STEPHANIE M. CABARCAS ${ }^{1}$, JI ZHENG ${ }^{1}$, LEI SUN ${ }^{1}$, LESLEY A. MATHEWS $^{1}$, \\ XIAOHU ZHANG ${ }^{1}$, HONGSHENG LIN ${ }^{1,2}$ and WILLIAM L. FARRAR ${ }^{1}$ \\ ${ }^{1}$ Cancer Stem Cell Section, Laboratory of Cancer Prevention, National Cancer \\ Institute-Frederick, Center for Cancer Research, Frederick, MD 21702, USA; \\ ${ }^{2}$ Oncology Department, Guang An Men Hospital of China Academy of Chinese Medical Sciences, Beijing 100053, P.R. China
}

Received December 7, 2014; Accepted January 19, 2016

DOI: $10.3892 / \mathrm{ol} .2016 .4444$

\begin{abstract}
Recent evidence indicates that tumor-initiating cells (TICs), also called cancer stem cells (CSCs), are responsible for tumor initiation and progression, therefore representing an important cell population that may be used as a target for the development of future anticancer therapies. In the present study, Cryptotanshinone (CT), a traditional Chinese herbal medicine, was demonstrated to regulate the behaviors of LNCaP prostate cells and prostate LNCaP TICs. The results demonstrate that treatment with $\mathrm{CT}$ alters cellular proliferation, cell cycle status, migration, viability, colony formation and notably, sphere formation and down-regulation of stemness genes (Nanog, OCT4, SOX2, $\beta$-catenin, CXCR4) in TICs. The present study demonstrates that $\mathrm{CT}$ targets the LNCaP $\mathrm{CD} 44^{+} \mathrm{CD} 24^{-}$population that is representative of prostate TICs and also affects total LNCaP cells as well via down-regulation of stemness genes. The strong effect with which $\mathrm{CT}$ has on prostate TICs suggests that CT may potentially function as a novel natural anticancer agent that specifically targets TICs.
\end{abstract}

\section{Introduction}

The recent identification of cancer stem cells (CSCs) or tumor-initiating cells (TICs) in multiple types of human cancer provides a novel inroad to understanding tumorigenesis at the cellular level (1). Recent evidence supports the hypothesis that the TIC population is responsible for tumor initiation and that

Correspondence to: Dr William L. Farrar, Cancer Stem Cell Section, Laboratory of Cancer Prevention, National Cancer Institute-Frederick, Center for Cancer Research, 560 Frederick, MD 21702, USA

E-mail: farrar@mail.ncifcrf.gov

Dr Hongsheng Lin, Oncology Department, Guang An Men Hospital of China Academy of Chinese Medical Sciences, 5 XianGe Street, Xuan Wu, Beijing 100053, P.R. China

E-mail: drlinhongsheng@gmail.com

Key words: Cryptotanshinone, tumor-initiating cells, prostate cancer, stemness genes, Chinese medicine
TIC are defined by their ability to self-renew, differentiate and initiate tumors upon transplantation (2-8) In addition, it has been proposed that current drugs used to target cancer are only capable of targeting the differentiated cancer cells and available treatments have the capability to shrink and de-bulk tumors but are unable to target the TICs, the population responsible for tumor initiation. Unfortunately, this inability of current anti-cancer treatments to target TICs results in the re-establishment of the tumor by the remaining and viable TIC population (9). Hence, the TIC hypothesis provides a novel target for the treatment of cancer.

Prostate cancer is the third leading cause of cancer-associated mortalities among men, behind colon and lung cancer and leads all non-skin cancer malignancies. Prostate cancer is initially treated with androgen deprivation therapy by either surgical castration or medical castration with gonadotropin-releasing hormone agonists (10). However, the response to androgen deprivation therapy in the metastatic setting is transient and tumors progress to castration-resistant prostate cancer, which is marked by a gain-of-function in androgen receptor (AR) and AR reactivation. According to the TIC hypothesis, AR would be expressed in the prostate cancer stem cell since there would be genetic selection for gain-of-function changes in AR, such as AR gene amplification (11). TICs are emerging as being important in prostate cancer metastasis and are coming to the forefront as targets of therapy. The ability to purify TICs and study mechanism(s) which may be utilized to target TICs is very important in the development of future prostate cancer treatment. Hurt et al (12) showed that $\mathrm{CD} 44^{+} / \mathrm{CD} 24^{-}$cells purified from the $\mathrm{LNCaP}$ cell line were more clonogenic, tumorigenic, and invasive than the corresponding depleted cells. Duhagon et al (13) demonstrated that TICs can be enriched using a sphere formation assay resulting in the culture of prostatospheres (PSs). Furthermore, Duhagon et al (13) provided a genomic profile of PSs that coordinated with the genomic profile of the prostate $\mathrm{CD} 44^{+} \mathrm{CD} 24^{-}$TIC population demonstrating that PSs are representative of the TIC population. Klarmann et al (14) demonstrated that the invasive cells in the prostate $\mathrm{LNCaP}$ cell line are more tumorigenic in NOD/SCID mice compared with noninvasive cells and have a genomic profile similar to CD $44^{+} \mathrm{CD} 24^{-}$cells as well. Hence, the CD $44^{+} / \mathrm{CD} 24^{-}$cells, 
the PSs and the invasive cells in prostate cancer cell lines are all representative of prostate TICs. These populations of cells express high levels of stem cell-associated genes, including OCT3/4, BMI, $\beta$-catenin, and smoothened (SMO) which is characteristic of TICs. Additionally, TICs appear to be more resistant to conventional chemotherapies and radiation, thereby, contributing to the development of metastatic and resistant disease $(9,15)$. Given these considerations, the present study sought to investigate if prostate TICs can be targeted by Traditional Chinese Medicines (TCM) to result in the prevention of tumor initiation, progression and relapse.

Herbal therapies and products commonly used in TCM are attracting increasing attention in the field of cancer. The principles underlying TCM were established over thousands of years based on clinical experience and practice. In China, the majority of cancer patients use some form of Chinese medicine, including prescription medications and non-prescription medications (16). On a global level, it has been reported that more than half of all cancer patients now use some form of complementary/alternative medicine, yet the majority of these patients do not disclose this use to their physicians (17). There are numerous clinical reports indicating that patients benefit from TCM treatment including Lin et al (18), which observed 173 cases of non-small cell lung cancer (NSCLC) patients, post-surgery, with two years of treatment with standard chemoprevention alone or combined with TCM herbs: The result of this study indicated that the relapse and distant metastasis rate of patients in the TCM group was $45.09 \%$ and the control group was $50.6 \%$. Yang et al (19) evaluated the effectiveness of comprehensive TCM treatment in reducing the relapse and metastasis of stage II and III colorectal cancer based on conventional Western medicine (WM) therapy: In this study, 222 patients were recruited and assigned to two groups based on whether or not they were additionally treated with TCM comprehensive therapy. The relapse/metastasis rate in the combined group at 1-, 2-, 3-, 4-, and 5-years was $0(0 / 98)$, $2.04 \%(2 / 98), 11.69 \%(9 / 77), 14.06 \%$ (9/64), and $21.28 \%(10 / 47)$, respectively (18). In the group given $\mathrm{WM}$, the relapse/metastasis rates were $4.80 \%$ (5/104), 16.35\% (17/104), $21.65 \%$ (21/97), $25.93 \%$ (21/81), and 38.18\% (21/55), respectively, for 1-, 2-, 3-, 4- and 5-years (19). The median relapse/metastasis time was 26.5 months in the combined group and 16.0 months in the WM group. These two studies provide a strong foundation of evidence that TCM can prohibit the relapse and metastasis of cancer. Additionally, it has been previously shown that TCM therapy can also prevent tumorigenesis (20). Liang et al (21) demonstrated that the TCM Liuwei Dihuang Wan, can prohibit progression of the precancerous disease of esophageal cancer. In this specific study, 214 patients with hyperplasia of esophageal epithelial cells were treated with Liu wei Di Huang Wan and after 2 years, the cancerous changes in the Liu wei Di Huang Wan treatment group was $1.4 \%$, but in the placebo group was $6.3 \%$ (22).

Unfortunately, the active ingredients in the majority of TCM herbs and their mechanism(s) have not been identified. However, it is clear that TCM is capable of preventing tumorigenesis and both the relapse and metastasis of cancer (23). Previous studies have indicated that certain naturally occurring phytochemicals are cytotoxic to TICs, such as parthenolide (PTL) derived from suayule, can specifically target TICs in primary human acute myelogenous leukemia (AML) (24). Additional studies demonstrated that PTL has toxicity on both the side population and mammospheres isolated from breast cancer which are representative of TICs, and lastly, Kawasaki et al (25) demonstrated that PTL is cytotoxic to prostate TICs. The phytochemical sulphoraphane, derived from broccoli, can inhibit breast cancer TICs and down-regulate the Wnt/beta-catenin self-renewal pathway (26). Gossypol, a bioactive phytochemical produced by cotton plants, was effective at inhibiting prostate tumor-initiating cell-driven tumor growth in a NOD/SCID xenograft model (27).

Current evidence suggests that TICs are responsible for tumorigenesis, relapse and metastasis (9) and can be targeted using naturally occurring compounds, hence, the present study aimed to determine whether components of TCM medicine, which are often phytochemicals, could inhibit or eradicate prostate TICs as well. Cryptotanshinone (CT), an active component of the Danshen root, is a popular TCM herb used in the clinic to treat chronic hepatitis, coronary heart disease $(28,29)$ and cancers such as hepatic cancer (30) and leukemia (31). The evidence indictes that $\mathrm{CT}$ has biological effects ranging from anti-inflammatory, -bacterial, -fibrotic, -oxidative, -mutagenic, and -platelet aggregation activities (29,32-34). There are a few reports on the antitumor effect of $\mathrm{CT}$, which include in vitro studies from Gong et al (35) that demonstrated that CT can inhibit the growth of human prostate cancer cell lines in a dose-dependent manner via cell cycle arrest and induction of apoptosis. In addition, Park et al (36) demonstrated that CT can suppress Bcl-2 expression and augment Fas sensitivity in DU145 cells. Further work indicates that JNK and p38 MAPK act upstream of Bcl-2 in Fas-treated DU145 cells and that CT can significantly block activation of these kinases (36). Shin et al (37) showed that CT is a potent anti-cancer agent and has antitumor activity through the inhibition of STAT3. Notably, biological behaviors such as cell migration and invasion are related to TICs, and there are reports indicating that CT has the ability to block invasion of bovine aortic endothelial cells induced by bovine fibroblast growth factor (bFGF) (38) and could function in inhibiting leukocyte chemo tactic migration (39). Taken together, the present study hypothesized that CT has the potential to target prostate TICs and investigated if CT was capable of targeting TICs derived from the LNCap prostate cell line. The results provide evidence that CT can target TICs and selectively inhibit their proliferation. Furthermore, the present study presents data that indicates CT driven inhibition of TICs occurs by regulating the expression of stemness genes that are associated with the self renewing ability of TICs. Based on this data, CT, an important TCM compound, has a potential effect in targeting TICs and it may provide an alternative means of treatment and options in the investigation for TIC targeting drugs.

\section{Materials and methods}

Cells and media. LNCaP cells were obtained from American Type Culture Collection (Manassas, VA, USA). Cells were maintained in RPMI-1640 with $10 \%$ fetal bovine serum (FBS), 2 mM L-glutamine and penicillin and streptomycin (all, Gibco ${ }^{\circledR}$; Thermo Fisher Scientific, Inc., Waltham, MA, USA). 
Assay of cell viability. Cells were plated at a density of 1,000 cells per well in a 96-well plate and viability was measured using Cell-Titer Glo assay (Promega Corporation, Madison, WI, USA). The Cell-Titer Glo reagent was added to each well and equilibrated for $30 \mathrm{~min}$ before measurements were taken. Luminescence was measured using an Infinite M200 plate reader (Tecan Group, Ltd., Männedorf, Switzerland).

Flow cytometric analysis and cell sorting. LNCaP cells were detached with trypsin (Gibco ${ }^{\circledR}$; Thermo Fisher Scientific, Inc., Waltham, MA, USA), washed once in FACs buffer [PBS containing 1-2\% bovine serum albumin (BSA; Gibco ${ }^{\circledR}$; Thermo Fisher Scientific, Inc., Waltham, MA, USA)], then stained with $5 \mu$ l of Invitrogen anti-CD24-FITC (mouse monoclonal; catalog no., MHCD2401-4; Thermo Fisher Scientific, Inc.) and $0.5 \mu \mathrm{l}$ of antibody per $10^{6}$ cells of anti-CD44-PE (mouse monoclonal; catalog no., 12-0441-82; eBioscience, Inc., San Diego, CA, USA) and incubated at $4^{\circ} \mathrm{C}$ for $15 \mathrm{~min}$. Following incubation, cells were washed twice with FACs buffer. For flow cytometric sorting, cells were re-suspended in FACs buffer at $20 \times 10^{6}$ cells $/ \mathrm{ml}$ and separated on an Aria cell sorter (BD Biosciences, San Jose, CA, USA). Live cells were gated on the basis of forward and side scatter, and single cells were gated on the basis of forward scatter and pulse width. Gates were determined by analysis of unstained cells, isotype specific stains, and single stains (WinMDI version 2.9; BD Biosciences). The $\mathrm{CD} 44^{+} \mathrm{CD} 24{ }^{-}$cells were not assessed for purity due to the low numbers of cells obtained.

Apoptosis assay. LNCaP cells were treated with or without varying concentrations of $\mathrm{CT}(0,2.5,5$ and $10 \mu \mathrm{M})$. After $48 \mathrm{~h}$, cells were collected and a quantitative apoptotic death assay was performed using Annexin V and propidium iodide (PI) staining. After trypsinization, the cells were re-suspended in the binding buffer with FITC-conjugated Annexin V and PI (BD Biosciences) for $20 \mathrm{~min}$ at room temperature in the dark. All samples were then FACS analyzed on an Aria cell sorter as described above to distinguish early-apoptotic cells, late-apoptotic and necrotic cells.

Cell cycle analysis. In total, $1 \times 10^{4}$ cells were seeded and treated with or without CT (catalog no., 10852-200806; National Institutes for Food and Drug Control, Beijing, China) at different doses according to the results of the cell viability assay $(0,2.5,5$ and $10 \mu \mathrm{M})$. Following treatment, $1 \times 10^{6}$ cells were fixed in ice cold $70 \%$ ethanol overnight. Following fixation, cells were centrifuged (5 min; $100 \mathrm{x} \mathrm{g}$ ) and re-suspended in PBS containing $40 \mu \mathrm{g} / \mathrm{ml}$ propidium iodide and $100 \mu \mathrm{g} / \mathrm{ml}$ RNAse A (Sigma-Aldrich, St. Louis, MO, USA) and incubated at $37^{\circ} \mathrm{C}$ for $1 \mathrm{~h}$. Samples were then FACS analyzed on an Aria cell sorter as described above and cell cycle analysis was performed.

Wound healing. The cells were seeded in a 12-well tissue culture dish at a concentration of $1 \times 10^{5}$ cells/well and maintained in RPMI-1640. After the cells reached 80-90\% confluency, the tip of a micropipette was used to wound the cells, creating a linear and cross-stripe scrape $2 \mathrm{~mm}$ apart. The cells were washed with PBS to remove floating cellular debris and re-fed for an additional $24 \mathrm{~h}$ with or without $\mathrm{CT}$ treatment $(1.25,2.50$ and
$5.00 \mu \mathrm{M})$. Images of wound closure or cell migration were captured when the scrape wound was introduced and $24 \mathrm{~h}$ after wounding, using an IX70 inverted microscope equipped with a digital camera (Olympus Corporation, Tokyo, Japan).

Soft agar colony assay. Cells were seeded at a concentration of 1,000 cells and suspended in RPMI-1640+10\% FBS containing $0.6 \%$ agarose (Sigma-Aldrich) and overlaid onto a 12-well plate containing a solidified bottom layer of RPMI-1640+10\% FBS plus agarose. Once the top layer solidified, $200 \mu \mathrm{l}$ of medium was placed on top to keep the plates moist. The plates were incubated for 2 weeks until colonies were visible. The plates were stained with $5 \mathrm{mM}$ MTT (Sigma-Aldrich) at $37^{\circ} \mathrm{C}$ for $1 \mathrm{~h}$, then counted and imaged by using GelCount ${ }^{\mathrm{TM}}$ automatic plate scanner (Oxford Optronics Ltd., Abingdon, UK) and GelCount Version 0.025.1 software (Oxford Optronics).

Sphere formation assay. In order to obtain prostatospheres from LNCaP cells, the exponentially growing cultures were dissociated to single cells by standard trypsinization, washed three times with PBS and plated in stem cell medium [SCM; Dulbecco's Modified Eagle Medium F12 (Gibco ${ }^{\circledR}$; Thermo Fisher Scientific, Inc.), $10 \mathrm{ng} / \mathrm{ml}$ bFGF (Sigma-Aldrich), $20 \mathrm{ng} / \mathrm{ml}$ endothelial growth factor (Sigma-Aldrich), $5 \mathrm{mg} / \mathrm{ml}$ insulin (Sigma-Aldrich), and 0.4\% BSA] supplemented with $1 \%$ KO serum replacement (Invitrogen; Thermo Fisher Scientific, Inc.) at a density of 1,000 cells $/ \mathrm{ml}$ in tissue culture treated flasks. After approximately 7 days, spheres were counted and analyzed using a GelCount ${ }^{\mathrm{TM}}$ automatic plate scanner (Oxford Optronics) and GelCount Version 0.025.1 software (Oxford Optronics).

Gene expression analysis. Total RNA isolation was performed using TRIzol reagent $\left(\mathrm{Gibco}^{\circledR}\right.$; Thermo Fisher Scientific, Inc.) on untreated LNcap cells, CT-treated LNcap cells, untreated CSCs cells that were enriched from LNcap cells and CT-treated CSCs cells that were enriched from LNcap cells. cDNA was synthesized with Invitrogen SuperScript III First-Strand Synthesis System for RT-PCR (Thermo Fisher Scientific, Inc.) using random hexamers and following the manufacturer's instructions. Analysis of gene expression by reverse transcription quantitative-polymerase chain reaction (RT-qPCR) was performed using TaqMan ${ }^{\mathrm{TM}}$ Gene Expression assays (Nanog assay ID, Hs04399610_g1; SOX-2 assay ID, Hs00367969_m1; OCT4 assay ID, Hs00999632_g1; BMI1 assay ID, Hs00995536_m1; MMP9 assay ID, Hs00234579_ m1; NFкB1 assay ID, Hs00765730_m1; $\beta$-catenin assay ID, Hs00355049_m1; CXCR4 assay ID, Hs00607978_s1; $\beta$-actin assay ID, Hs01060665_g1; Thermo Fisher Scientific, Inc.) in a StepOne Real-Time PCR machine (Thermo Fisher Scientific, Inc.). The cycling conditions were as follows: $10 \mathrm{~min}$ at $95^{\circ} \mathrm{C}$; and 40 cycles of $95^{\circ} \mathrm{C}$ for $15 \mathrm{sec}$ and $60^{\circ} \mathrm{C}$ for $1 \mathrm{~min}$. Relative mRNA expression levels were calculated as $2^{-\Delta \Delta C q}$ and were normalized against $\beta$-actin (40). The experiment was repeated three times.

Western blot analysis. Total protein was isolated from LNCaP cells using RIPA lysis buffer (Thermo Fisher Scientific Inc.) and quantified using the BCA protein assay kit (Pierce Biotechnology, Inc., Rockford, IL, USA). A total of $20 \mu \mathrm{g}$ of 
A

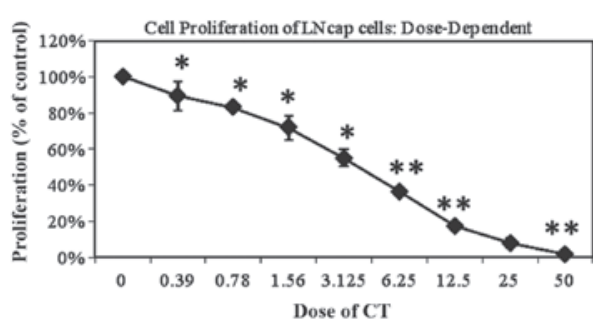

C

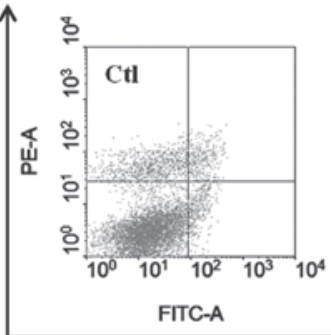

$\stackrel{8}{0}$
B
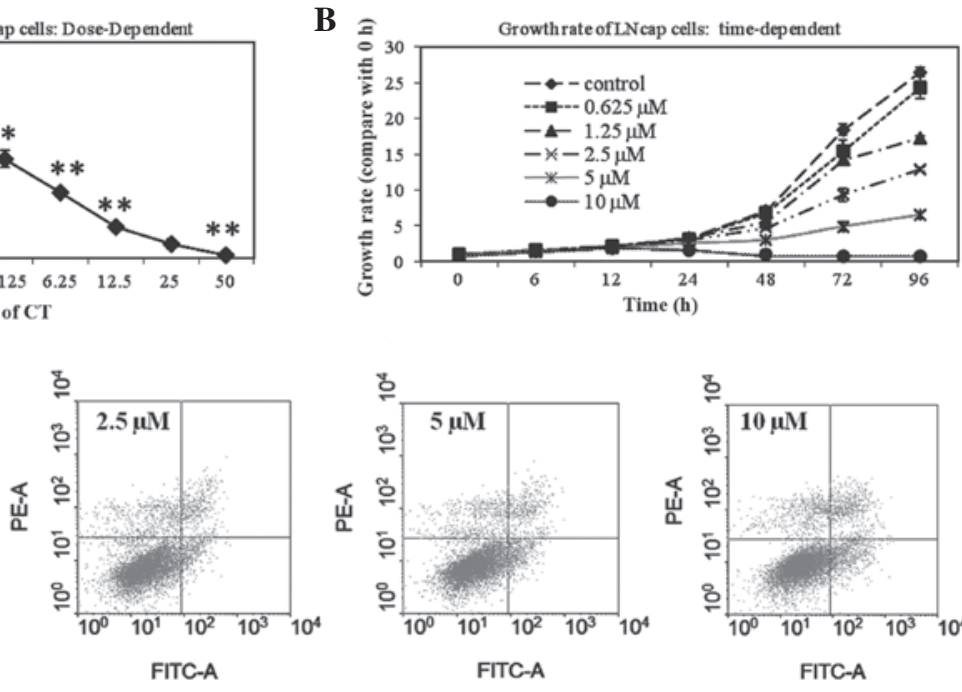
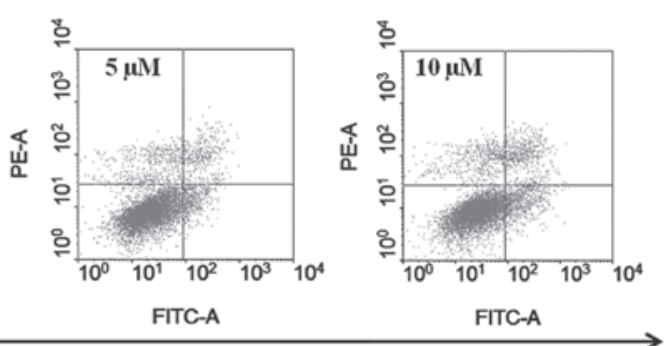
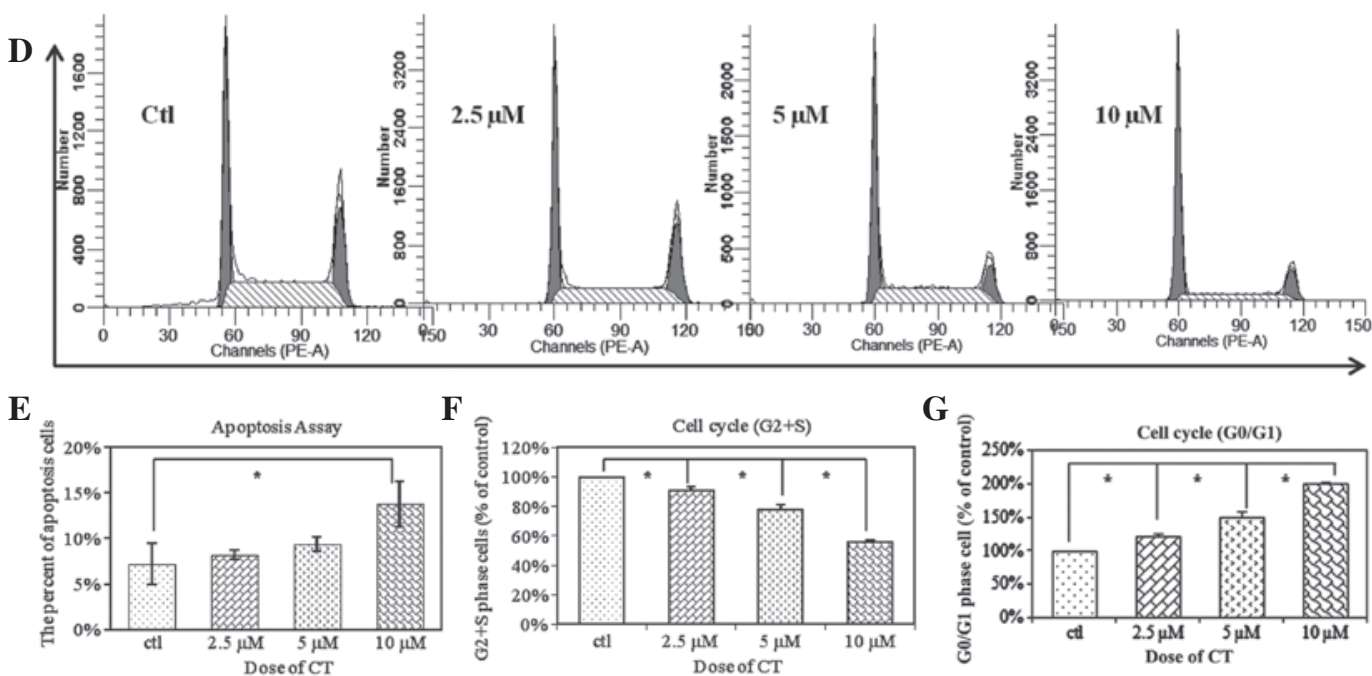

Figure 1. CT changes the biological behaviors of total LNCaP cells. (A) LNCaP cells were treated with an increasing dose of CT ranging from 0.39 to $50 \mu \mathrm{M}$ for $48 \mathrm{~h}$. CT inhibited the proliferation of total LNCaP cells in a dose-dependent manner $\left({ }^{*} \mathrm{P}<0.05 ;{ }^{* *} \mathrm{P}<0.01\right.$. (B) LNCaP cells were observed over $6-96 \mathrm{~h}$ and treated with $0-10 \mu \mathrm{M} \mathrm{CT}$ as indicated. The $\mathrm{IC}_{50}$ of $\mathrm{CT}$ is $5 \mu \mathrm{M}$; inhibition was time-dependent and greatest after $8 \mathrm{~h}$. (C) LNCap cells were treated with increasing doses of CT $(2.5 \mu \mathrm{M}, 5 \mu \mathrm{M}$ and $10 \mu \mathrm{M})$. FACS analysis demonstrated that CT induced the cell apoptosis of Total LNCaP cell in a dose-dependent manner. (D) FACS analysis demonstrated that treatment with CT results in LNCaP cell cycle arrest, in a dose-dependent manner. (E) Statistical analysis of apoptosis demonstrates there is a significant difference between the control group and the $10 \mu \mathrm{M} \mathrm{CT}$ treated groups ("P<0.01). (F) The relative percentages of $\mathrm{CT}$ treated LNCaP cells in the $\mathrm{S}$ and $\mathrm{G} 2 / \mathrm{S}$ phases of the cell cycle. The percentage of $\mathrm{CT}$ treated cells distributed at the G2/S phase was significantly reduced in a dose-dependent manner from 69.73 to $63.5,54.25$ to $39.05 \%$ after $48 \mathrm{~h}$ of treatment with $2.5,5$ and $10 \mu \mathrm{M} \mathrm{CT}$, respectively ("P<0.01). (G) A total of $36.55 \%$, $45.75 \%$, and $60.95 \%$ of LNCaP cells were distributed at the G0/G1 phase after $48 \mathrm{~h}$ of treatment with $2.5,5$ and $10 \mu \mathrm{M}$ CT, respectively. This was in comparison to the $30.27 \%$ of untreated cells in $\mathrm{G} 0 / \mathrm{G} 1$ phase $\left({ }^{*} \mathrm{P}<0.01 ;{ }^{* *} \mathrm{P}<0.05\right)$. FACS, fluorescent activated cell sorting; CT, cryptotanshinone.

protein extract was loaded per lane into a $4-20 \%$ Tris-glycine gel (Invitrogen; Thermo Fisher Scientific Inc.), transferred to a polyvinylidene fluoride membrane (EMD Millipore, Billerica, MA, USA), blocked in 5\% BSA and incubated with the following primary polyclonal rabbit antibodies from Abcam (Cambridge, UK): Anti-Nanog (catalog no., ab80892; dilution, 1:1,000); anti-actin (catalog no., ab194952; dilution, 1:10,000); anti-CXCR4 (catalog no., ab93478; dilution, 1:1,000); anti- $\beta$-catenin (catalog no., ab6302; dilution, 1:5,000); anti-SOX2 (catalog no., ab97959; dilution, 1:1,000); and anti-OCT4 (catalog no., ab125949; dilution, 1:1,000). All secondary antibodies obtained from LI-COR $\left(\right.$ IRDye ${ }^{\circledR}$ goat anti-rabbit IgG; catalog no., 926-32221; LI-COR Biosciences, Lincoln, NE, USA). Blots were scanned using the LI-COR Odyssey IR Imaging System.
Statistical analysis. Unless specified, all experiments were performed in triplicate and were repeated at least twice. Data is expressed as mean values, standard error of the mean or standard deviation and were analyzed by analysis of variance. SPSS version 10.0 (SPSS Inc., Chicago, IL, USA) was used for analysis. The level of significance was set at $\mathrm{P}<0.05$.

\section{Results}

The anti-proliferative effects of CT on LNCaP cells. To determine whether $\mathrm{CT}$ inhibited cellular proliferation of the $\mathrm{LNCaP}$ line, cells were treated with increasing concentrations of CT as indicated and cell viability was assessed. Fig. 1A demonstrates that $\mathrm{CT}$ inhibited cellular proliferation at 0.39 to $50 \mu \mathrm{M}$ doses for $48 \mathrm{~h}$. Fig. 1B demonstrates that $\mathrm{CT}$ inhibition of $\mathrm{LNCaP}$ 
A

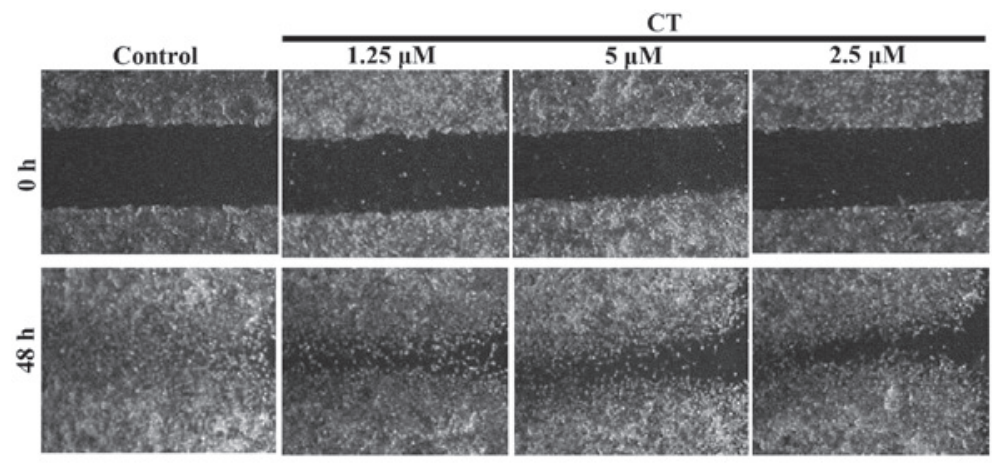

$\mathbf{B}$

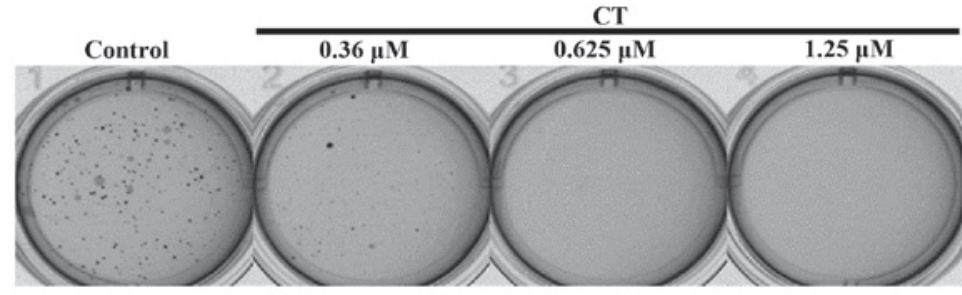

C

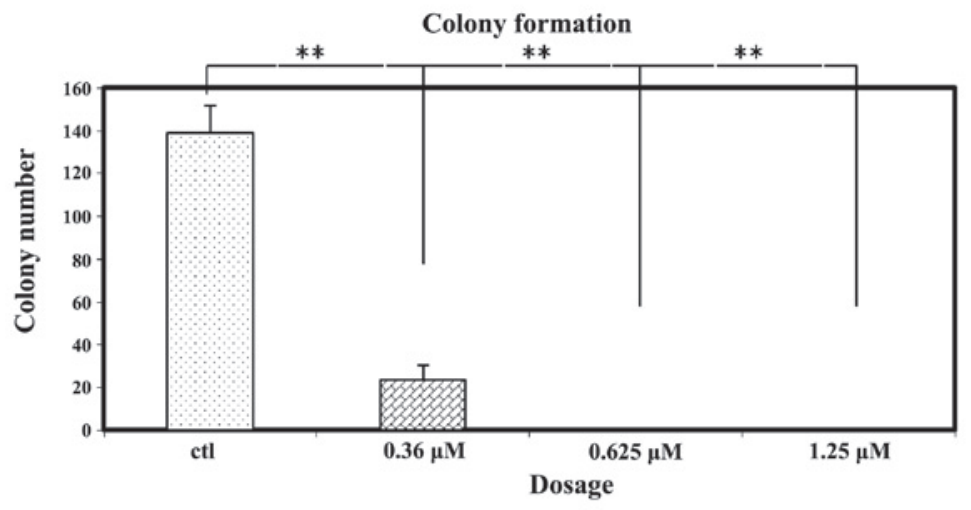

Figure 2. CT inhibits the wound healing and the colony formation behaviors of total LNCap cells: (A) Wound healing assay was performed on LNCap cells using increasing doses of CT. For the untreated cells, migration occurred and the wound was healed in 48 h; however, in cells treated with CT, cell migration was partially inhibited. (B) Colony formation efficiency of LNCaP cells was inhibited by a serial dilution of CT and (C) quantification revealed the difference to be statistically significant $\left({ }^{(* *} \mathrm{P}<0.01\right)$. Data from a representative experiment (from a total of three) are shown. CT, cryptotanshinone.

proliferation is time-dependent as a time period of 6-96 $\mathrm{h}$ was tested at various doses as indicated. The $\mathrm{IC}_{50}$ of CT is $5 \mu \mathrm{M}$ and is most effective after $48 \mathrm{~h}$. The anti-proliferative effect of CT on LNCaP cells was a dose and time-dependent. Based on these results, the subsequent experiments were performed with a dose of $5 \mu \mathrm{M}$ and the time period the cells are treated with $\mathrm{CT}$ varies based on the experiment performed and is indicated.

To further determine whether the inhibition in proliferation by CT is due to an induction in apoptosis, LNCaP cells were treated with $\mathrm{CT}$ and analyzed apoptosis using FACS analysis. Fig. 1C demonstrates that CT has an apoptotic effect on LNCaP cells and this effect is dose dependent. However, there was a significant difference among the control group and the $10 \mu \mathrm{M}$ CT treated groups (Fig. 1E). Based on this observation, the anti-proliferative effects were analyzed of CT was due to perturbation of the cell cycle. LNCaP cells were treated with different concentrations of CT: The number of CT treated LNCaP cells distributed at the G2/S phase after $48 \mathrm{~h}$ of treatment with $2.5,5$ and $10 \mu \mathrm{M}$ CT was also significantly decreased from 69.73 to $63.51 \%, 54.25 \%$, and $39.05 \%$, respectively in a dose dependent manner (Fig. 1F; $\mathrm{P}<0.01$ ). A total of $36.55,45.75$ and $60.95 \%$ of the cells were distributed at the
G0/G1 phase after $48 \mathrm{~h}$ of treatment with $2.5,5$ and $10 \mu \mathrm{M} \mathrm{CT}$, respectively; this was in comparison to the $30.27 \%$ of untreated cells in G0/G1 (Fig. 1G; P<0.01). This data indicates that CT inhibits cellular proliferation by inducing G0/G1 phase arrest in cancer cells.

CT affects biological behaviors of total LNCaP cells. To determine if CT could affect specific biological behaviors of LNCap cells such as the ability to migrate, a wound healing assay was performed on LNCap cells treated with CT (Fig. 2A). After making a wound, LNCap cells were treated with various concentrations of CT, as indicated, and then the wound was inspected microscopically over time as the cells migrated to fill the damaged area. For the untreated cells, migration occurred and the wound was healed in $48 \mathrm{~h}$; however, in cells treated with CT, cell migration was partially inhibited. The data suggests that the level of migration was affected in a dose dependent manner.

An additional characteristic of cancer cells that affects their biological behavior is the ability to form colonies in anchorage independent conditions. The present study investigated whether $\mathrm{CT}$ has the ability to affect colony formation. 
A

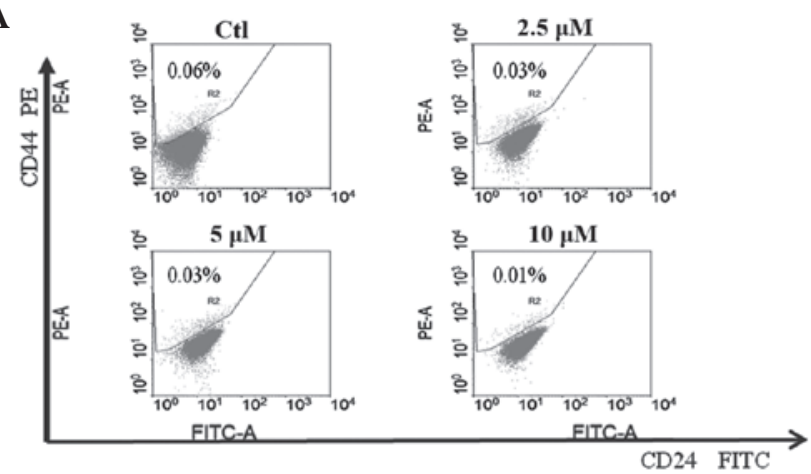

$\mathbf{C}$

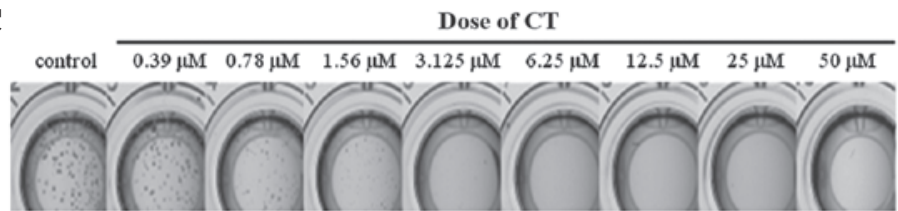

B

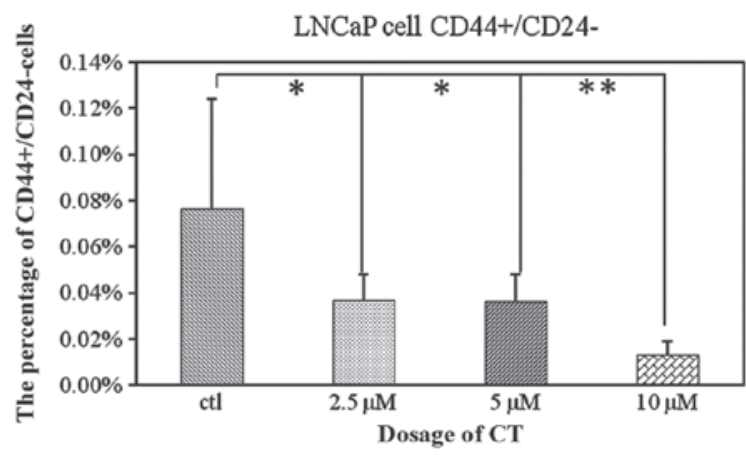

D

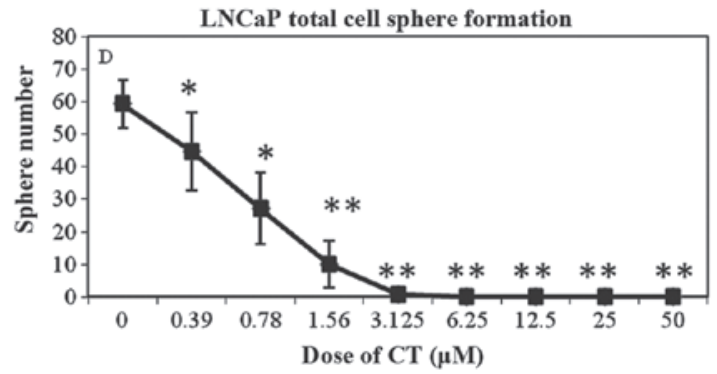

$\mathbf{F}$

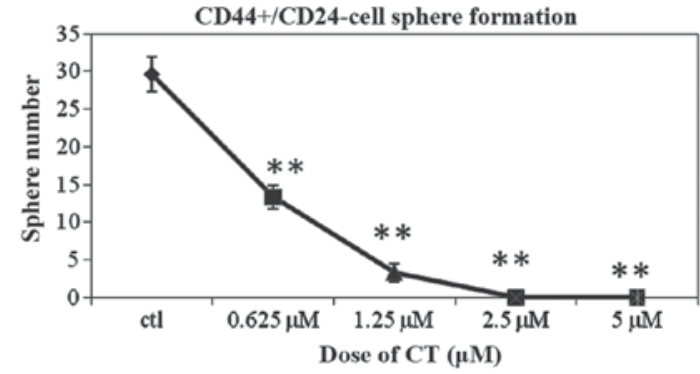

Figure 3. CT targets LNCaP TICs. (A) FACS analysis was performed to determine the percentage of CD44+CD24- cells after treatment with increasing doses of CT $(2.5,5$ and $10 \mu \mathrm{M})$. Data from a representative experiment (from a total of three) are shown. (B) Percentage of CD44 ${ }^{+} \mathrm{CD} 24^{-} \mathrm{LNCaP}$ cells compared to untreated control. The percentage reduced in a dose dependent manner, however no statistically significant difference was observed between the control and CT treated groups (C) Sphere formation assay quantification was performed using increasing doses of CT. (D) The sphere forming ability was significantly inhibited by CT while the dose up to $1.5 \mu \mathrm{M},\left({ }^{*} \mathrm{P}<0.05 ;{ }^{* *} \mathrm{P}<0.01\right)$. (E) Sphere formation assay of CD44 ${ }^{+} / \mathrm{CD} 24^{-}$cells was performed using increasing doses of CT. (F) The sphere forming ability were inhibited by $\mathrm{CT}$ while the dose up to $0.625 \mu \mathrm{M}\left({ }^{* *} \mathrm{P}<0.05\right.$; $\left.{ }^{*} \mathrm{P}<0.01\right)$. FACS, fluorescent activated cell sorting; CT, cryptotanshinone; TICs, tumor initiating cells

Fig. 2B and $\mathrm{C}$ demonstrates that the colony formation efficiency of LNCaP cells was significantly inhibited by $\mathrm{CT}$ at very low doses $(0.36,0.625$ and $1.25 \mu \mathrm{M})$. Notably, at the $\mathrm{IC}_{50}$ concentration of $5 \mu \mathrm{M}$, colony formation did not occur (data not shown); therefore, a serial dilution of CT was performed and it was observed that colonies do not form following CT treatment when the dose is as low as $0.625 \mu \mathrm{M}$.

CT affects the biological behaviors of LNCaP TICs. Based on the above data, CT has the ability to inhibit cellular proliferation of LNCaP cells in a time and dose dependent manner; reduced the percentage of cells which are in the proliferative phase of the cell cycle; prolonged and partially inhibited the ability to migrate after cell wound healing; induced apoptosis of LNCaP cells and lastly, inhibited colony formation in soft agar. As previously stated, there are various phenotypes associated with prostate TICs such as cell migration and soft agar colony formation $(13,14)$. Hence, we sought to investigate if CT has the ability to specifically regulate the biological behaviors of LNCaP TICs.

Our laboratory has previously shown that the $\mathrm{CD} 44^{+} \mathrm{CD} 24$ cell population is the TIC population in the $\mathrm{LNCaP}$ cell line and the present study sought to investigate if $48 \mathrm{~h}$ CT treatment would alter the percentage of $\mathrm{CD} 44^{+} \mathrm{CD} 24^{-}$cells (14). A dose-dependent decrease of this subpopulation was observed (Fig. 3A); $0.08 \pm 0.05 \%, 0.04 \pm 0.01 \%, 0.04 \pm 0.01 \%$ and $0.01 \pm 0.01 \%$ of the total cells reflect the $\mathrm{CD} 44^{+} / \mathrm{CD} 24$ population after $48 \mathrm{~h}$ of treatment with $0,2.5,5$ and $10 \mu \mathrm{M}$ $\mathrm{CT}$, respectively. However, these results were not statistically significant (Fig. 3B). Based on these observations, this decrease may be a result of $\mathrm{CT}$ functioning as an inhibitor of TIC viability, TIC proliferation or as an inducer of differentiation, resulting in an overall reduction of the TIC population.

Previously our laboratory has shown that the sphere formation assay can enrich for TICs of LNCaP cells (13), hence, the total cells were cultured in highly defined stem cell media as previously described and cultured with or without CT. The results demonstrate that $\mathrm{CT}$ inhibit sphere formation of LNCaP cells at a dose of $1.5 \mu \mathrm{M}$ (Fig. 3C and D), a dose previously shown to have little effect on total LNCap viability (less than $30 \%$ Fig. 1A). Based on these observations, it was hypothesized that CT could specifically inhibit the proliferation or self-renewing ability of TICs. To confirm whether CT could 

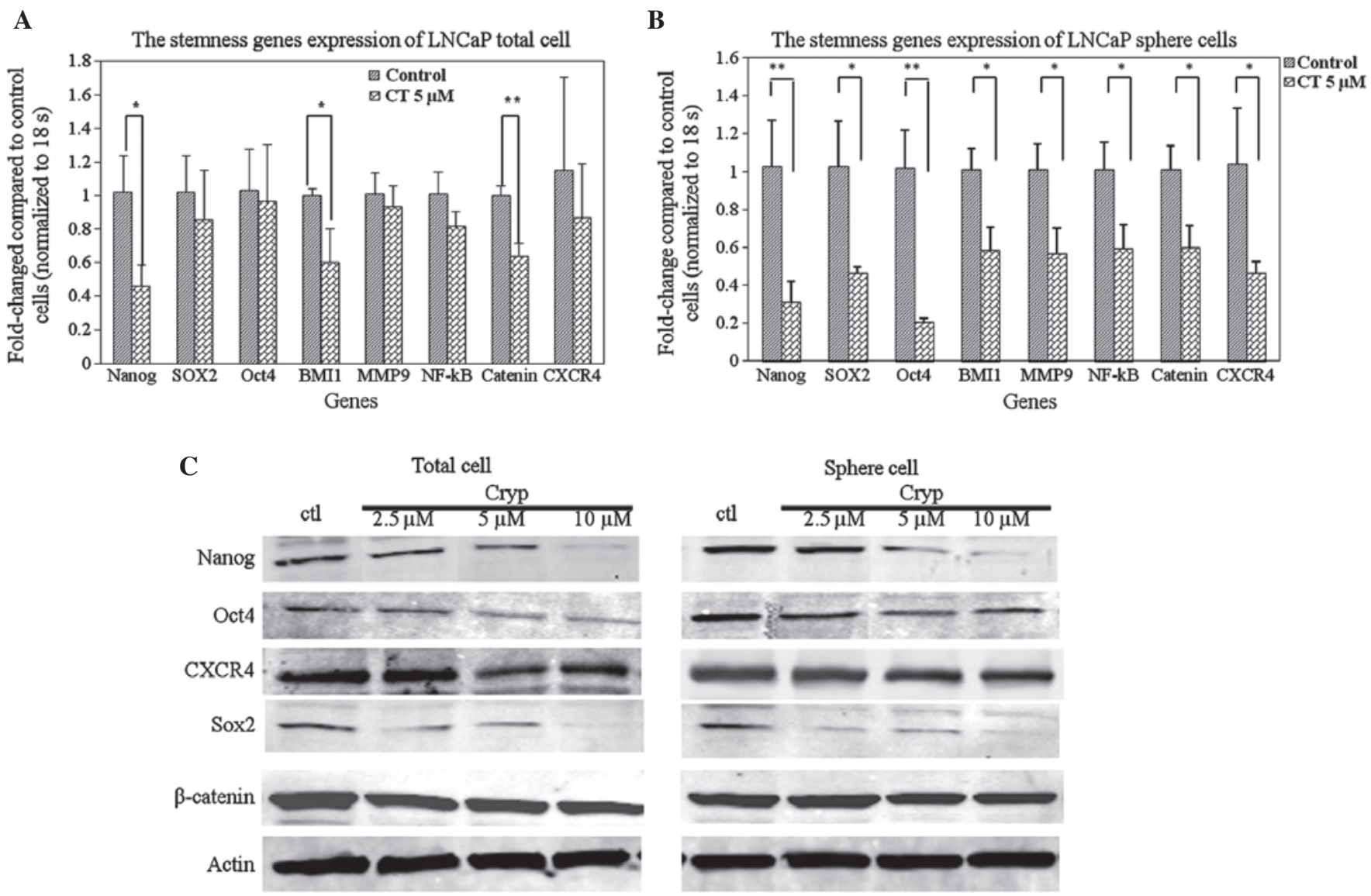

Figure 4. CT affects mRNA and protein levels of stemness genes in both total and TIC LNCaP cells. (A) Total LNCaP cells were treated with CT for $24 \mathrm{~h}$ and RT-qPCR was performed. Statistically significant reductions in the mRNA expression of Nanog, BMI1 and Catenin, were observed ("P $<0.05$; $\left.{ }^{* *} \mathrm{P}<0.01\right)$. (B) LNCaP spheres were treated with CT for $24 \mathrm{~h}$ and RT-qPCR was performed ("P<0.05). Data is normalized to 18srRNA. (C) Western blot analysis was performed on both total and sphere LNCaP cells to determine expression levels of Nanog, OCT4, Sox 2, $\beta$-catenin and CXCR4. The left volume are Total $\mathrm{LNCaP}$ cell and the right volume are sphere cells. Data from a representative experiment (from a total of three) are shown. CT, cryptotanshinone; TICs, tumor initiating cells; RT-qPCR, reverse transcription-quantitative polymerase chain reaction.

indeed inhibit TIC self-renewal, the LNCaP CD44+CD24population was isolated by FACs sorting and cultured in SCM with or without CT. As shown in Fig. 3E and F, the ability to form spheres was decreased from $29.99 \pm 2.3$ in the control group to $13.3 \pm 1.52$ in the $0.625 \mu \mathrm{M} \mathrm{CT}$ group, $3.33 \pm 1.15$ in the $1.25 \mu \mathrm{M} \mathrm{CT}$ group, and 0 in the $2.5 \mu \mathrm{M}$ and $5 \mu \mathrm{M} \mathrm{CT}$ group. Based on these data, evidence is provided that $\mathrm{CT}$ inhibits the sphere forming ability of $\mathrm{CD} 44^{+} \mathrm{CD} 24^{-}$cells. This evidence supports the hypothesis that $\mathrm{CT}$ can target the self-renewing ability of TICs.

CT regulates stemness genes associated with LNCaP TICs. To further understand the possible molecular mechanisms by which CT can regulate LNCaP TIC self-renewal, the present study investigated whether CT can inhibit the expression of TIC related genes implicated in self-renewal by RT-qPCR and western blot analysis. Nanog, SOX2 and Oct3/4 genes are important transcription factors orchestrating the self-renewal of stem cells (41); therefore, these factors and additional stem associated factors were selected. As shown in Fig. 4A, it was demonstrated that $\mathrm{CT}$ treatment reduced the expression levels of certain stemness genes in total cells, specifically the expression of Nanog, BMI1 and $\beta$-catenin: A statistically significant decrease of mRNA levels was observed between the control and $5 \mu \mathrm{M}$ CT treated groups $(\mathrm{P}<0.05, \mathrm{P}<0.05$, $\mathrm{P}<0.01$, respectively). To further investigate the hypothesis that CT specifically affects TICs by decreasing the expression of stemness genes, RT-qPCR was performed on LNCaP cell spheres treated with or without CT. Fig. 4B demonstrates that treatment with $\mathrm{CT}$ resulted in a decrease of expression of stemness genes in $\mathrm{LNCaP}$ spheres. The decrease in expression was statistically significant in all the detected genes $(\mathrm{P}<0.01)$. Lastly, western blot analyses confirmed the observations in the RT-qPCR. CT treatment reduced Nanog, SOX2 and OCT4 protein expression levels in a dose-dependent manner in total (Fig. 4C, left) and sphere cells (Fig. 4C, right).

The Wnt signaling pathway is important in embryogenesis (42), and is also essential for the self-renewal of stem cells by preventing cellular differentiation. Our data shows that $\beta$-catenin expression is down-regulated by CT (Fig. 4C) and further confirms that $\mathrm{CT}$ affects important regulatory factors involved in self-renewal of prostate TICs. The survival and maintenance of stem cells requires a balance between the processes of both self-renewal and differentiation. This is hypothesized to be regulated by a niche or protective microenvironment that is required to anchor the stem cells $(43,44)$. CXCR4, a G-protein coupled receptor, has recently been confirmed as a TIC marker as well and is expressed at a 
significantly higher level in this population compared to the non-TICs (45-48). To determine if CT could affect CXCR4 expression, the expression levels of CXCR4 were analyzed in LNCaP TICs at the mRNA and protein level. The results indicated that CXCR4 is down-regulated at the mRNA and protein levels in the total and TIC population (Fig. 4). Based on the ability of CT to regulate stem associated genes and CXCR4, it is possible that CT also regulates biological behaviors associated with the function of the SDF1/CXCR4 axis such as migration and metastasis.

\section{Discussion}

Our previous work indicates that both sphere forming and $\mathrm{CD} 44^{+} \mathrm{CD} 24-$ populations in $\mathrm{LNCaP}$ cells reflect a population with a capacity to undergo self-renewal and initiate tumor formation which are major properties of TICs $(12,13)$. An additional characteristic of TICs is the upregulation and increased expression of stem associated transcription factors such as Nanog, SOX2 and OCT4, which are found to modulate embryonic stem cell self-renewal (41). The evidence supporting the aggressiveness and ability of these cells to initiate tumors and function in metastasis has led to the study of these TICs as an important potential target for cancer therapy. The present study provides several lines of evidence that CT has the ability to inhibit the self-renewing ability of prostate TICs. The present study demonstrated that CT treatment reduced the percentage of CD44+CD24- prostate cancer cells (Fig. 3A) and reduced the number of $\mathrm{LNCaP}$ derived prostatospheres (Fig. 3B and C). Lastly, it was demonstrated that $\mathrm{CT}$ can regulate several genes known to regulate $\mathrm{LNCaP}$ TICs, including SOX2, Nanog and OCT4 which are critical transcription factors in the regulation of both ES and TIC cell properties (38) (Fig. 4). Collectively, this data indicates that $\mathrm{CT}$ can reduce and effect the TIC population.

As recent studies have shown, Nanog, SOX2 and OCT4 serve crucial roles in stem cell self-renewal. These coordinated transcription factor networks involving OCT4, SOX2, and Nanog have currently emerged as the master regulatory mechanisms of stem cell self-renewal and differentiation (49). It has been shown that knockdown of OCT4 can induce ES cells to differentiate into trophectoderm-like cells (50) and knockdown of SOX2 results in ES cell differentiation $(51,52)$. MicroRNAs responsible for the regulation of OCT4, SOX2, and Nanog coding regions are found to modulate embryonic stem cell differentiation as well (41). Notably, miR-302 which can target OCT4/SOX2/Nanog has been shown to have a role in converting differentiated cells to induced pluripotent stem cells $(53,54)$. However, their dysfunction in cancer may contribute to the maintenance of an undifferentiated proliferative phenotype by preventing the expression of differentiation genes and allowing the expression of genes promoting stem cell renewal $(55,56)$. Further evidence supporting the critical role of OCT4, SOX2, Nanog and Lin28 in stem cells were seen when transfection of these factors in 293 FT cells demonstrated an impaired ability to differentiate and form immature ectodermal tumors after they were transplanted into nude mice (57). In a lung adenocarcinoma model, OCT4 and Nanog are highly expressed in $\mathrm{CD}_{133^{+}}$but not in the CD133- population (58) and in a glioblastoma model, Nanog appears to be critical in the ability of undifferentiated stem cells to undergo self-renewal and is the most differentially expressed (59). The ability of CT to inhibit OCT4, SOX2, Nanog by CT confirms that CT can target the self-renewal ability of prostate TICs.

Another important gene in TIC regulation is $\beta$-catenin and our data further indicates that CT can down-regulate expression of $\beta$-catenin as well. The Wnt signaling pathway is essential for the maintenance of the majority of tissue stem cell compartments by preventing cellular differentiation such as seen in intestinal and hematopoietic stem cells (60). $\beta$-catenin is a key protein in the regulation of this pathway, therefore, inhibition of $\beta$-catenin by $\mathrm{CT}$ further confirms that $\mathrm{CT}$ can target the self-renewal ability of prostate TICs.

In order for stem cells to survive and maintain the balance between self-renewal and differentiation, a niche or protective microenvironment is required to anchor the stem cells $(43,44,61)$ CXCR4 is a G-protein coupled receptor that is expressed constitutively in a wide variety of normal tissues, including lymphatic tissues, thymus, brain, spleen, stomach, and small intestine (62). Within the microenvironment, both stromal derived factor (SDF-1) and its receptor CXCR4 is essential for the cell anchoring process $(15,63)$. It is well documented that disseminated prostate cancer cells express CXCR4 and can home to sites where SDF is present such as the bone and lymph nodes (63). Recently, CXCR4 was detected on TICs and mRNA levels were found to be significantly higher in this population in comparison to the non-TICs (44-48). The upregulation of CXCR4 cell surface expression corresponded to a significant increase in EMT in response to SDF1- $\alpha$ in vitro $(64,65)$. In the present study, CT was shown to down-regulate CXCR4 expression in total $\mathrm{LNCaP}$ cells and the TIC population; hence, it is possible CT can further regulate TICs by regulating the CXCR4-SDF1 axis and disrupting its ability to interact with the microenvironment. However, further work needs to be performed to confirm this.

In conclusion, this is the first report demonstrating a role for CT as a regulator and inhibitor of prostate TICs. CT can specifically inhibit the self-renewal of TICs by targeting key transcriptional regulators. The data demonstrating that $\mathrm{CT}$ can regulate these factors indicates that $\mathrm{CT}$ has the potential to function as a natural anti-cancer agent targeting prostate TICs.

\section{Acknowledgements}

The authors acknowledge Ms Kathleen Noer, Ms Roberta Matthai and Ms Guity Mohammadi for their expert technical assistance in FACs separation and analysis of the cells lines. The authors also thank Dr. Jeffery White, Dr. Libin Jia for support for this project in the Office of Cancer Complementary and Alterative Medicine, National Cancer Institute (Rockville, MD, USA). This work has been funded in part with Federal funds from the National Cancer Institute, National Institutes of Health, U.S. (contract no., HHSN261200800001E). This research was supported in part by the National Natural Science Foundation of China (grant no., 81473467). The content of this paper does not necessarily reflect the views or policies of the Department of Health and Human Services, nor does mention of trade names, commercial products, or organizations imply endorsement by the US Government. 


\section{References}

1. Harris MA, Yang H, Low BE, Mukherjee J, Guha A, Bronson RT, Shultz LD, Israel MA and Yun K: Cancer stem cells are enriched in the side population cells in a mouse model of glioma. Cancer Res 68: 10051-10059, 2008.

2. Al-Hajj M, Wicha MS, Benito-Hernandez A, Morrison SJ and Clarke MF: Prospective identification of tumorigenic breast cancer cells. Proc Natl Acad Sci USA 100: 3983-3988, 2003.

3. Haraguchi N, Inoue H, Tanaka F, Mimori K, Utsunomiya T, Sasaki A and Mori M: Cancer stem cells in human gastrointestinal cancers. Hum Cell 19: 24-29, 2006.

4. Kondo T, Setoguchi T and Taga T: Persistence of a small subpopulation of cancer stem-like cells in the C6 glioma cell line. Proc Natl Acad Sci USA 101: 781-786, 2004.

5. Ponti D, Costa A, Zaffaroni N, Pratesi G, Petrangolini G, Coradini D, Pilotti S, Pierotti MA and Daidone MG: Isolation and in vitro propagation of tumorigenic breast cancer cells with stem/progenitor cell properties. Cancer Res 65: 5506-5511, 2005.

6. Prince ME, Sivanandan R, Kaczorowski A, Wolf GT, Kaplan MJ, Dalerba P, Weissman IL, Clarke MF and Ailles LE: Identification of a subpopulation of cells with cancer stem cell properties in head and neck squamous cell carcinoma. Proc Natl Acad Sci USA 104: 973-978, 2007

7. Singh SK, Hawkins C, Clarke ID, Squire JA, Bayani J, Hide T, Henkelman RM, Cusimano MD and Dirks PB: Identification of human brain tumour initiating cells. Nature 432: 396-401, 2004.

8. Wicha MS, Liu S and Dontu G: Cancer stem cells: An old idea-a paradigm shift. Cancer Res 66: 1883-1890; discussion 1895-1896, 2006.

9. Reya T, Morrison SJ, Clarke MF and Weissman IL: Stem cells, cancer, and cancer stem cells. Nature 414: 105-111, 2001.

10. Sharifi N, Gulley JL and Dahut WL: Androgen deprivation therapy for prostate cancer. JAMA 294: 238-244, 2005.

11. Sharifi N, Hurt EM and Farrar WL: Androgen receptor expression in prostate cancer stem cells: Is there a conundrum? Cancer Chemother Pharmacol 62: 921-923, 2008.

12. Hurt EM, Kawasaki BT, Klarmann GJ, Thomas SB and Farrar WL: CD44+ CD24(-) prostate cells are early cancer progenitor/stem cells that provide a model for patients with poor prognosis. Br J Cancer 98: 756-765, 2008

13. Duhagon MA, Hurt EM, Sotelo-Silveira JR, Zhang X and Farrar WL: Genomic profiling of tumor initiating prostatospheres. BMC Genomics 11: 324, 2010.

14. Klarmann GJ, Hurt EM, Mathews LA, Zhang X, Duhagon MA, Mistree T, Thomas SB and Farrar WL: Invasive prostate cancer cells are tumor initiating cells that have a stem cell-like genomic signature. Clin Exp Metastasis 26: 433-446, 2009.

15. Dean M, Fojo T and Bates S: Tumour stem cells and drug resistance. Nat Rev Cancer 5: 275-284, 2005.

16. Yu S, Li N and Lv J: Investigation of the use of Chinese medicine in patients with malignant conditions. Zhong Guo Zhong Yi Yao Xin Xi Za Zhi 17: 1-3, 2010 (In Chinese).

17. Smith M and Boon HS: Counseling cancer patients about herbal medicine. Patient Educ Couns 38: 109-120, 1999.

18. Lin HS and Zhang Y: Evidence-based medical study of TCM on no small cell lung cancer. Shi Jie Ke Xue Ji Shu-Zhong Yi Yao Xian Dai Hua Za Zhi 10: 121-125, 2008 (In Chinese).

19. Yang YF, Ge JZ, Wu Y, Xu Y, Liang BY, Luo L, Wu XW, Liu DQ, Zhang X, Song FX and Geng ZY: Cohort study on the effect of a combined treatment of traditional Chinese medicine and western medicine on the relapse and metastasis of 222 patients with stage I and III colorectal cancer after radical operation. Chin J Integr Med 14: 251-256, 2008

20. Zhao L, Yan S and Jiang T: Inhibitory effect of liuwei dihuang decoction on induced mutation and spontaneous tumor. Zhong Xi Yi Jie He Za Zhi 10: 433-435, 1990 (In Chinese).

21. Liang JT, Yan CY, Wang SF, Wu G and Wen PG: Experimental cancer research Liuwei Dihuang Wan prevention. Zhong Yi Za Zhi 6: 71-74, 1983 (In Chinese).

22. He XX, Yan C and Endi W: The analysis of the cyto-diagnosis results of liuweidihuangwan treating esophagel precancerous disease and gastric precancerous disease. Hebei Yiyao 9: 4-6, 1998 (In Chinese)

23. Zhang Y and Lin HS: Tumor stem cells may be the final target of traditional Chinese medicine in preventing cancer recurrence and metastasis. Zhongguo Zhong Xi Yi Jie He Za Zhi 29: 461-463, 2009 (In Chinese).
24. Guzman ML, Rossi RM, Karnischky L, Li X, Peterson DR, Howard DS and Jordan CT: The sesquiterpene lactone parthenolide induces apoptosis of human acute myelogenous leukemia stem and progenitor cells. Blood 105: 4163-4169, 2005.

25. Kawasaki BT, Hurt EM, Kalathur M, Duhagon MA, Milner JA, Kim YS and Farrar WL: Effects of the sesquiterpene lactone parthenolide on prostate tumor-initiating cells: An integrated molecular profiling approach. Prostate 69: 827-837, 2009.

26. Li Y, Zhang T, Korkaya H, Liu S, Lee HF, Newman B, Yu Y, Clouthier SG, Schwartz SJ, Wicha MS and Sun D: Sulforaphane, a dietary component of broccoli/broccoli sprouts, inhibits breast cancer stem cells. Clin Cancer Res 16: 2580-2590, 2010.

27. Volate SR, Kawasaki BT, Hurt EM, Milner JA, Kim YS, White J and Farrar WL: Gossypol induces apoptosis by activating p53 in prostate cancer cells and prostate tumor-initiating cells. Mol Cancer Ther 9: 461-470, 2010.

28. Stickel F, Brinkhaus B, Krähmer N, Seitz HK, Hahn EG and Schuppan D: Antifibrotic properties of botanicals in chronic liver disease. Hepatogastroenterology 49: 1102-1108, 2002.

29. Zhou L, Chow M and Zuo Z: Improved quality control method for Danshen products-consideration of both hydrophilic and lipophilic active components. J Pharm Biomed Anal 41: 744-750, 2006.

30. Peng ZS, Rao RS, Ni YW, Tan YS and Gong ZF: Hepatic artery blood medicine treatment of advanced liver cancer efficacy. Zhong Xi Yi Jie He Za Zhi 13: 330-332, 1993 (In Chinese).

31. Zhang X, Liu ZH, Liu Y, Zhang ZH, Wan CC, Xia YJ, Jiang Z Jin YJ, Wang YW and Lu GQ: The effect of compound prescription salvia miltiorrhiza inoculation fluid (CPSMIF) in the treatment of leukemia patients combined with acute tumor dissolution synthesis (ATDS). Xian Dai Zhong Liu Yi Xue Za Zhi 18: 1204-1206, 2010 (In Chinese).

32. Kim SY, Moon TC, Chang HW, Son KH, Kang SS and Kim HP: Effects of tanshinone I isolated from salvia miltiorrhiza bunge on arachidonic acid metabolism and in vivo inflammatory responses. Phytother Res 16: 616-620, 2002.

33. Ng TB, Liu F and Wang ZT: Antioxidative activity of natural products from plants. Life Sci 66: 709-723, 2000.

34. Sung HJ, Choi SM, Yoon Y and An KS: Tanshinone IIA, an ingredient of salvia miltiorrhiza BUNGE, induces apoptosis in human leukemia cell lines through the activation of caspase-3. Exp Mol Med 31: 174-178, 1999.

35. Gong Y, Li Y, Lu Y, Li L, Abdolmaleky H, Blackburn GL and Zhou JR: Bioactive tanshinones in salvia miltiorrhiza inhibit the growth of prostate cancer cells in vitro and in mice. Int J Cancer 129: 1042-1052, 2011.

36. Park IJ, Kim MJ, Park OJ, Park MG, Choe W, Kang I, Kim SS and Ha J: Cryptotanshinone sensitizes DU145 prostate cancer cells to Fas(APO1/CD95)-mediated apoptosis through Bcl-2 and MAPK regulation. Cancer Lett 298: 88-98, 2010.

37. Shin DS, Kim HN, Shin KD, Yoon YJ, Kim SJ, Han DC and Kwon BM: Cryptotanshinone inhibits constitutive signal transducer and activator of transcription 3 function through blocking the dimerization in DU145 prostate cancer cells. Cancer Res 69: 193-202, 2009.

38. Hur JM, Shim JS, Jung HJ and Kwon HJ: Cryptotanshinone but not tanshinone IIA inhibits angiogenesis in vitro. Exp Mol Med 37: 133-137, 2005.

39. Zhou Z, Zheng J and Xu W: Study on the effect of ofloxacin and tanshinone IIA on human leukocyte chemotactic migration in vitro. Zhongguo Yi Xue Ke Xue Yuan Xue Bao 19: 232-235, 1997 (In Chinese).

40. Livak KJ and Schmittgen TD: Analysis of relative gene expression data using real-time quantitative PCR and the 2(-Delta Delta C(T)) Method. Methods 25: 402-408, 2001.

41. Tay Y,Zhang J, Thomson AM,Lim B and Rigoutsos I: MicroRNAs to Nanog, OCT4 and SOX2 coding regions modulate embryonic stem cell differentiation. Nature 455: 1124-1128, 2008.

42. Funayama N, Fagotto F, McCrea P and Gumbiner BM: Embryonic axis induction by the armadillo repeat domain of beta-catenin: Evidence for intracellular signaling. J Cell Biol 128: 959-968, 1995.

43. Li L and Neaves WB: Normal stem cells and cancer stem cells: The niche matters. Cancer Res 66: 4553-4557, 2006.

44. Avigdor A, Goichberg P, Shivtiel S, Dar A, Peled A, Samira S, Kollet O, Hershkoviz R, Alon R, Hardan I, et al: CD44 and hyaluronic acid cooperate with SDF-1 in the trafficking of human CD34+ stem/progenitor cells to bone marrow. Blood 103: 2981-2989, 2004 
45. Ehtesham M, Mapara KY, Stevenson CB and Thompson RC: CXCR4 mediates the proliferation of glioblastoma progenitor cells. Cancer Lett 274: 305-312, 2009.

46. Liu G, Yuan X, Zeng Z, Tunici P, Ng H, Abdulkadir IR, Lu L, Irvin D, Black KL and Yu JS: Analysis of gene expression and chemoresistance of CD133+ cancer stem cells in glioblastoma. Mol Cancer 5: 67, 2006.

47. Salmaggi A, Boiardi A, Gelati M, Russo A, Calatozzolo C, Ciusani E, Sciacca FL, Ottolina A, Parati EA, La Porta C, et al: Glioblastoma-derived tumorospheres identify a population of tumor stem-like cells with angiogenic potential and enhanced multidrug resistance phenotype. Glia 54: 850-860, 2006.

48. Soeda A, Park M, Lee D, Mintz A, Androutsellis-Theotokis A, McKay RD, Engh J, Iwama T, Kunisada T, Kassam AB, et al Hypoxia promotes expansion of the CD133-positive glioma stem cells through activation of HIF-1alpha. Oncogene 28: 3949-3959, 2009.

49. Kashyap V, Rezende NC, Scotland KB, Shaffer SM, Persson JL, Gudas LJ and Mongan NP: Regulation of stem cell pluripotency and differentiation involves a mutual regulatory circuit of the NANOG, OCT4 and COX2 pluripotency transcription factors with polycomb repressive complexes and stem cell microRNAS. Stem Cells Dev 18: 1093-1108, 2009.

50. Niwa H, Miyazaki J and Smith AG: Quantitative expression of Oct-3/4 defines differentiation, dedifferentiation or self-renewal of ES cells. Nat Genet 24: 372-376, 2000.

51. Chew JL, Loh YH, Zhang W, Chen X, Tam WL, Yeap LS, Li P, Ang YS, Lim B, Robson P and Ng HH: Reciprocal transcriptional regulation of Pou5f1 and SOX2 via the OCT4/SOX2 complex in embryonic stem cells. Mol Cell Biol 25: 6031-6046, 2005.

52. Rodda DJ, Chew JL, Lim LH, Loh YH, Wang B, Ng HH and Robson P: Transcriptional regulation of nanog by OCT4 and SOX2. J Biol Chem 280: 24731-24737, 2005.

53. Lin SL, Chang DC, Chang-Lin S, Lin CH, Wu DT, Chen DT and Ying SY: Mir-302 reprograms human skin cancer cells into a pluripotent ES-cell-like state. RNA 14: 2115-2124, 2008.

54. Wilson KD, Venkatasubrahmanyam S, Jia F, Sun N, Butte AJ and Wu JC: MicroRNA profiling of human-induced pluripotent stem cells. Stem Cells Dev 18: 749-758, 2009.
55. Esquela-Kerscher A and Slack FJ: Oncomirs-MicroRNAS with a role in cancer. Nat Rev Cancer 6: 259-269, 2006.

56. Volinia S, Calin GA, Liu CG, Ambs S, Cimmino A, Petrocca F, Visone R, Iorio M, Roldo C, Ferracin M, et al: A MicroRNA expression signature of human solid tumors defines cancer gene targets. Proc Natl Acad Sci USA 103: 2257-2261, 2006.

57. Oka Y, Nakajima K, Nagao K, Miura K, Ishii N and Kobayashi H. 293FT cells transduced with four transcription factors (OCT4, SOX2, NANOG and LIN28) generate aberrant ES-like cells. J Stem Cells Regen Med 6: 149-156, 2010.

58. Chiou SH, Wang ML, Chou YT, Chen CJ, Hong CF, Hsieh WJ, Chang HT, Chen YS, Lin TW, Hsu HS and Wu CW: Coexpression of OCT4 and nanog enhances malignancy in lung adenocarcinoma by inducing cancer stem cell-like properties and epithelial-mesenchymal transdifferentiation. Cancer Res 70: 10433-10444, 2010.

59. Field M, Alvarez A, Bushnev S and Sugaya K: Embryonic stem cell markers distinguishing cancer stem cells from normal human neuronal stem cell populations in malignant glioma patients. Clin Neurosurg 57: 151-159, 2010.

60. Kléber M and Sommer L: Wnt signaling and the regulation of stem cell function. Curr Opin Cell Biol 16: 681-687, 2004

61. Weidt C, Niggemann B, Kasenda B, Drell TL, Zänker KS and Dittmar T: Stem cell migration: A quintessential stepping stone to successful therapy. Curr Stem Cell Res Ther 2: 89-103, 2007.

62. Chang L and Karin M: Mammalian MAP kinase signalling cascades. Nature 410: 37-40, 2001.

63. Hermann PC, Huber SL, Herrler T, Aicher A, Ellwart JW, Guba M, Bruns CJ and Heeschen C: Distinct populations of cancer stem cells determine tumor growth and metastatic activity in human pancreatic cancer. Cell Stem Cell 1: 313-323, 2007.

64. Cronin PA, Wang JH and Redmond HP: Hypoxia increases the metastatic ability of breast cancer cells via upregulation of CXCR4. BMC Cancer 10: 225, 2010.

65. Onoue T, Uchida D, Begum NM, Tomizuka Y, Yoshida H and Sato M: Epithelial-mesenchymal transition induced by the stromal cell-derived factor-1/CXCR4 system in oral squamous cell carcinoma cells. Int J Oncol 29: 1133-1138, 2006. 